\title{
ТЕХНОЛОГИЧЕСКИЕ ПРИОРИТЕТЫ И МЕХАНИЗМЫ ЭКОНОМИЧЕСКОГО РАЗВИТИЯ РОССИИ В УСЛОВИЯХ ТРАНСФОРМАЦИИ РЫНОЧНЫХ ОТНОШЕНИЙ НА СОВРЕМЕННОМ ЭТАПЕ
}

\author{
(c) 2020 Глисин Алексей Федорович \\ кандидат экономических наук, \\ доцент Департамента Корпоративных финансов и корпоративного управления \\ Финансовый университет при Правительстве Российской Федерации, Россия, Москва \\ E-mail: alglisin@gmail.com
}

\begin{abstract}
Переход на инновационно-технологическое развитие предполагает изменение научных основ функционирования российской экономики. С этой целью экономике нашей страны необходимо учитывать опыт, прежде всего, промышленно развитых стран и, в тоже время, руководствоваться некоторыми из правил поведения производителей продуктов и их потребителей (как ресурсов производства), характерных для периода функционирования советской экономики на микроуровне (до проведения перестройки), учитывая различия между весомостью таких факторов при директивном управлении экономикой и рыночными условиями ее функционирования. Развитие технологизации, осуществляемое на основе инициативы самих субъектов производственной деятельности, позволит экономике нашей страны добиться более высокого уровня развития институтов в сравнении с уровнем развития, характерным для современной экономики промышленно развитых стран, создаст прочное научно-технологическое основание для повышения уровня суверенизации экономики и проведения комплекса мероприятий на макроуровне, которые могут быть предусмотрены государственным руководством, для достижения экономикой России в рамках мирового экономического порядка статуса технологической державы.
\end{abstract}

Ключевые слова: инновации, межотраслевое сотрудничество, технологические факторы развития экономики, интегрированный технологический менеджмент.

«...нужны новые идеи и технологии...» П. Самуэльсон, 2002 2.

Еще в 2008 году Президент России В.В. Путин в программной речи, произнесенной на расширенном заседании Госсовета, определил стратегию развития экономики России до 2020 года и представил свое видение дальнейшего развития страны на долгосрочную перспективу. При этом, особое внимание было обращено на необходимость изменения существующего «сырьевого сценария развития» экономики. Единственной реальной альтернативой такому ходу событий является стратегия инновационного развития страны. Поясняя данный термин, В.В. Путин прежде всего выделил «наиболее эффективное применение знаний и умений людей для постоянного улучшения технологий, экономических результатов, жизни общества в целом» [Жить по-человечески. Владимир Путин выступил на расширенном заседании Госсовета // Российская газета. 2008. 9 февраля].

Анализируя эти высказывания, необходимо отметить, что уже тогда Президент подчеркивал необходимость перехода экономики России к новому этапу развития. Основу этого этапа должна составлять нравственная экономика - «экономика доверия». А технологическое и духовное развитие создаст благоприятный доброжелательный социально-психологический климат, исключающий принятие коррупционных антисоциальных управленческих решений на всех уровнях единого народно-хозяйственного пространства.

По конституции РФ - «Российская Федерация - социальное государство, политика которого направлена на создание условий, обеспечивающих достойную жизнь и свободное развитие человека». И хотя понятие «достойная жизнь человека» не раскрывается, логично и принято считать, что важнейшим фактором достойной жизни человека является экономический потенциал страны, производительность труда за счет 
интеллектоемкости, уровень технологического развития производства конкурентоспособной продукции (профессионально подготовленного человеческого капитала, материалов, оборудования, информации, услуг).

Для сравнения и анализа надо отметить ВВП в развитых странах мира по состоянию на сегодняшний день по данным МВФ (Список стран по ВВП 2019, http://global-finances.ru/vvp-stranmira-2019/):

1. США - 21,344

2. Китай - 14,216

3. Япония - 5,176

4. Германия $-3,963$

5. Индия $-2,971$

6. Великобритания - 2,829

7. Франция - 2,761

8. Италия $-2,025$

9. Бразилия $-1,960$

10. Канада - 1,739

11. Южная Корея $-1,656$

12. Россия - 1,610

13. Испания - 1,429

14. Австралия - 1,417

15. Мексика - 1,241

16. Индонезия - 1,100

17. Нидерланды - 0,914

18. Саудовская Аравия - 0,762

19. Швейцария $-0,707$

20. Турция - 0,706

К этой динамике хорошо подходит цитата П.Ф. Друкера «...нет слаборазвитых стран, а есть плохо управляемые экономики»

В настоящее время стратегия инновационного развития стала основой экономической политики государственного руководства [48]. Однако, по мнению специалистов, пока нет четкого представления о необходимых первичных изменениях современного развития российской экономики, связанных с проблемой разработки нового механизма производственной деятельности. При этом, механизм производственной деятельности понимается как взаимосвязь и взаимообусловленность технологических факторов развития нравственной экономики.

По мнению ученых-экономистов, копирование опыта промышленно развитых стран - не лучший вариант развития России, что в мировой экономике чаще эффективным становится экономическое развитие тех стран, которые идут своим путем [22, 33, 40, 41]. Поэтому, надо не только использовать опыт промышленно разви- тых стран, на чем в настоящее время сосредоточены российские исследователи рынка, но и те элементы развития российской экономики до перестройки, которые могут быть использованы в условиях рынка.

Возникает актуальная задача: определить возможность устойчивого развития экономики, исходя из тех технологических факторов, которые могут быть свойственны российской экономике [12, 13].

Главным, по мнению ученых, является тот факт, что механизм производственной деятельности в настоящее время явно не соответствует тому уровню развития, который может обеспечить России экономический суверенитет в условиях «воспроизводства ресурсов производства», как новой категории экономики, и создать новый механизм производственной деятельности $[32,40]$.

Поэтому именно инновационно-технологическое развитие экономики России должно быть связано с коренным изменением экономической структуры: увеличением значимости в производстве и потреблении высокотехнологичных продуктов во всех отраслях экономики, что позволит превратить Россию в современную технологическую державу.

Сформировавшийся в настоящее время механизм производственной деятельности предполагает опору в развитии экономики на отдельные отрасли-доноры, в то время как инновационное развитие должно предполагать повышение научно-технического уровня всех отраслей экономики.

Именно взаимоотношения между людьми, между производителями продуктов и потребителями этих продуктов как ресурсов производства, являются движущим моментом производственного и общественного развития, определяя особую роль такого института, как современный технологический менеджмент [12, 14, 15].

В конце 2016 года была наконец утверждена стратегия научно-технологического развития РФ. Ее цель - ускорение технологического развития России за счет увеличения количества предприятий, включаемых в процесс воспроизводства, в частности, за счет повышения значимости и удельного веса высокотехнологичной продукции. Этот путь в качестве конечной цели предполагает место России в рамках мирового экономического порядка как равноправной, независимой державы, внешнеэкономические 
связи которой определяются, как и у многих промышленно-развитых стран, большей значимостью высокотехнологичных продуктов производства, а не сырьевой направленностью экономики [48].

Этот путь предполагает не проведение отдельных мероприятий по «косметическому» совершенствованию имеющегося в России механизма функционирования экономики, а коренное изменение критериев и принципов функционирования производителей в условиях рынка и их технологического развития. На протяжении многих веков наши предки из Киевской, Новгородской и Московской Руси прошли лишь три стадии развития цивилизации: натуральное родовое хозяйство, крепостничество и наемничество. Огромное большинство народа никогда не обладало экономической свободой, так как средства производства, земля и природные богатства всегда принадлежали «элите» (начальникам), охранялись стражами (армия, полиция, бюрократия). Народ должен был работать за «пайку», а если кто-то не хотел мириться с этой системой, его уничтожали.

Длительный геноцид почти убил в народе сам дух свободы, предпринимательства, желание быть самодеятельным гражданином, но главное - длительное угнетение привело к непониманию самой цели и смысла жизни. Трудно считать «дистанционно» управляемому человеку свою жизнь счастливой, если каждый день он думает только о том, как добыть средства пропитания, чем прикрыть свое тело и как получить крышу над головой.

Представители существующих властных структур, как правило не имеющие современного экономического и технологического образования, закрепляют наемничество с отделением человека от результатов его труда.

Эти набирающие опасную силу процессы происходят в условиях реализации идеи новой централизованной системы управления государством и обществом и усугубляют негативные процессы в экономике, доводя ее до «устойчивого» кризисного состояния. Это, в свою очередь, позволяет антиобщественным по своим целям, коррумпированным и мафиозным структурам заявлять о своих претензиях на политическое управление обществом.

Как показала практика, мировая и российская, создание «заказных» акционерных обществ не позволяет передать огромную соб- ственность на высокотехнологичные средства производства непосредственным производителям товаров и услуг, права которых должны быть защищены законом. Это сдерживает рост производительности труда, технологическое развитие производства конкурентоспособной продукции и ее реализацию на рынке, рост доходов широких слоев населения и качество его жизни.

Много лет назад П.Ф. Друкер сформулировал до сих пор ни кем не опровергнутую истину - «В мире нет слаборазвитых стран, а есть плохо управляемые экономики» [20]. Уже сегодня интеллектуальная элита страны принципиально готова сконструировать проект системного управления не только коммерческой организацией, но и гражданским обществом в целом на принципах социального согласия и справедливости, обеспечивающей и гарантированную Конституцией РФ «достойную жизнь и свободное развитие человека» - главного заказчика и исполнителя проекта. Необходимым элементом такой системы должны быть организационно-правовые механизмы социально-технологического менеджмента организаций, стимулирующие высокоэффективный труд товаропроизводителя и постоянное технологическое развитие всех элементов производства в целом.

Без высокоэффективной стандартизированной работы государственных служащих, выполняющих регулирующие функции, невозможно успешное и безопасное существование слоя собственников малого и среднего бизнеса, невозможно существование материально обеспеченных слоев государственного аппарата и интеллигенции.

В России были примеры подобных инновационных проектов. Так Иннокентий Сибиряков, государственный интеллигент и предприниматель, век назад вложил часть своего миллионного состояния в научные проекты, в том числе на Валааме. «Мои миллионы, - писал И. Сибиряков,результат труда других людей. И я чувствую себя неправым, завладев их трудом.».

Поэтому именно на принципы, стандарты и организационно-правовые механизмы будущего проекта ложится основная моральная и социально-нравственная ответственность перед гражданским обществом.

Анализ отечественного опыта технологического развития показывает, что в бывшем СССР и России имелись и имеются существенные достижения в области создания прогрес- 
сивных технологий в различных областях ОПД, однако традиционной болезнью является слабое их внедрение в хозяйственную практику. Часто внедрение технологических достижений осуществляется в единичных случаях и в очень ограниченных масштабах, что иногда сводит на нет достижения их разработчиков. Многие прогрессивные технологии были разработаны еще в СССР, однако нашли практическое применение преимущественно в зарубежных странах.

О неудовлетворительном положении дел в области применения прогрессивных технологий свидетельствует тот факт, что до сих пор половина и более работ выполняется вручную в различных сферах деятельности (строительство, ЖКХ и др.) и эта проблема решается медленно. Использование отсталых технологий в производстве не только обусловливает тяжелые условия труда, но и допускает большие потери продукции, сырья и материалов.

Неудовлетворительное положение дел с технологическим развитием отраслей народного хозяйства связано не только с внедрением недостаточно эффективных технологий, но и с сокращением масштабов технического перевооружения производства. Наибольшую опасность для окружающей среды, наряду с вредными веществами, поступающими в воздушную и водную среду, представляют токсичные отходы, накапливаемые в отвалах, свалках и т.д.

Вместе с тем, как показывает зарубежный и отечественный опыт, эффективность затрат на прогрессивные технологии значительно выше, чем на другие мероприятия по внедрению новой техники. Статистические данные свидетельствуют, что при внедрении прогрессивных технологий повышается эффективность большинства социально-экономических показателей (рост прибыли, снижение себестоимости, экономия ресурсов, улучшение и сохранение окружающей среды и др.) в большей степени, чем в случае внедрения мероприятий по повышению технического уровня производства и выпускаемой продукции без совершенствования технологий.

Для народного хозяйства России в настоящее время характерно широкое распространение и использование устаревших, отсталых технологий на многих предприятиях и в организациях, что является часто основной причиной неудовлетворительных условий труда, низкой производительности труда, нерационального расхода ресурсов, выпуска устаревшей продукции низ- кого качества при ее высоких ценах и себестоимости; отсутствует эффективная система отбора и реализации прогрессивных технологий; многие новые технологии недостаточно отлажены.

Отсутствует заинтересованность предприятий, организаций и отдельных граждан в технологических нововведениях. Технологические инновации в начальной фазе их использования, как правило, вызывает повышенные затраты на период их освоения по сравнению с ранее применяемыми технологиями, снижение объемов производства, замену и переналадку технологического оборудования, переподготовку кадров [30, 31]. Такое повышение затрат снижает стимулирование отказа от ранее использовавшихся технологий, даже в случае их существенного устаревания, если этот отказ ничем не компенсируется. Отечественный и зарубежный технологический потенциал оказывается невостребованным и мало используется.

Отсутствует или несовершенен механизм обратной связи между мероприятиями по технологическому развитию ОПД и результатами реализации этих мероприятий. Наблюдается резкое замедление инвестиционных процессов в технологическом развитии, сокращение объемов финансирования технологической подготовки и технологического развития ОПД.

До сих пор явно недостаточен уровень технологического обучения и образования, уровень квалификации кадров по технологической подготовке и технологическому развитию многих видов ОПД. Работы по технологическому развитию ОПД не обеспечены кадрами необходимой специализации и квалификации [34].

Недостаточная технологическая подготовка многих видов ОПД ведет к частым нарушениям технологической дисциплины, ставшим причиной потерь огромного масштаба и многих катастроф.

Одним из следствий отсутствия механизмов реализации технологий стало отсутствие полноценного рынка технологий, механизма его формирования и развития. Владение технологиями во многих случаях монопольное, отсутствуют эффективные каналы спроса и предложения технологий, доля России в мировой торговле технологиями крайне незначительна $[8,9]$.

у большой части общества существует непонимание и недооценка роли и значения технологического развития России для решения многих современных и перспективных научно-техниче- 
ских, производственных, экономических, социальных и экологических проблем. Социальная потребность в объективно необходимом технологическом развитии ОПД часто отсутствует.

Слаба законодательная и правовая база технологического развития ОПД в России. Отсутствует законодательно закрепленная государственная политика технологического развития России; отсутствуют законы и нормативные акты, гарантирующие правовое обеспечение работ по технологическому развитию ОПд; нет пока надежных правовых гарантий отсутствия вредных последствий использования технологий, нарушающих условия жизнедеятельности человека и экологические требования.

Решение проблем технологического развития России осуществляется бессистемно, работы по технологическому развитию отдельных видов ОПД слабо увязаны с работами по технологическому развитию смежных видов ОПД, нет систематизации опыта технологического развития с доведением результатов его обобщения до всех заинтересованных пользователей; усилия технологических служб на уровне отдельных предприятий и организаций разобщены, недостаточно скоординированы или дублируются, работы выполняются стихийно $[7,10]$.

Одним из наиболее существенных недостатков работ по технологическому развитию ОПД в СССР и России является некомплексный подход к решению этой проблемы, когда разработка и реализация отдельных мероприятий не давали и не дают того эффекта, на который они рассчитаны [11]. При этом чаще всего проявляется неэффективность самих мероприятий (технологий, технических и управленческих решений) в несоответствии производственных и других условий требованиям эффективного функционирования нововведений. Отсутствие комплексности мероприятий влечет за собой отсутствие обеспечения перехода на более эффективные технологии данной и смежных видов ОПД. Отсутствие согласованности и совместимости смежных видов ОПД ведет к мнимой экономии средств и большим потерям при получении конечного результата. В сельском хозяйстве - это недополучение урожая и потери при хранении, транспортировке и переработке продукции, сводящие иногда на нет усилия по выращиванию продукции. В промышленности - это несогласованность и несовместимость возможностей машин, оборудования и выполняемых работ, а также сырья и материалов, квалификации рабочей силы. В социальной сфере, например, несоответствие между увеличением насыщения сложной бытовой техники и слабой ее ремонтной базой.

Комплексный системный подход к технологическому развитию ОПД требует перехода от планирования и проведения отдельных мероприятий к комплексным взаимоувязанным технологическим, социальным, правовым, экономическим и организационным решениям.

Особую актуальность приобретают такие факторы, как государственная научно-технологическая политика, определяющая главные направления технологического развития России, и обеспечивающая наиболее целесообразное и эффективное решение основных социально-экономических, экологических и других проблем в стране, как это делали в Германии, США, Японии, других развитых странах [23, 24, 25, 35].

Совершенствование структуры единого народнохозяйственного пространства должно предусматривать: специализацию работ по технологической подготовке и технологическому развитию ОПД, доведенную до уровня специальных отраслей технологостроения; переход от создания и применения отдельных средств и методов ОПД к созданию и применению технологий, технологических комплексов; создание, освоение и использование прогрессивных технологий во всех видах ОПД. Кроме того, необходимо постоянное совершенствование систем стандартизации и метрологии технологий и технологического развития ОПд, а также введение комплексной системы экспертизы и сертификации технологий. Необходима классификация технологий и технологических решений, а также обеспечение единства нормативно-технической документации на технологии и по технологическому развитию.

Необходимо особо подчеркнуть, что предстоит большая работа по созданию и совершенствованию национальной системы технологического менеджмента, обеспечивающей учет, анализ и прогнозирование технологического развития ОПД; интеграцию и взаимодействие отраслевых автоматизированных информационных систем технологического развития с использованием системы менеджмента качества и современных технологических стандартов.

Основной системный недостаток - отсутствует необходимая научно обоснованная методология, единая программа и эффективный 
механизм технологического развития России.

Для эффективного технологического развития экономики России необходимо также создание рынка технологий ОПД, углубление международного технологического сотрудничества России с высокоразвитыми странами мира, активное участие России в международном разделении труда по технологическому развитию ОПД, развитие технологической интеграции.

При этом необходимо использовать положительный опыт технологического развития многих стран мира.

Многие ученые и специалисты утверждают, что удержать народное хозяйство России от деградации без его технологического развития невозможно, но, несмотря на очевидную необходимость технологического развития народного хозяйства России, внимания решению этой проблемы уделяется явно недостаточно. Даже тот технологический потенциал России, который накоплен и пока существует, часто оказывается невостребованным или используется недостаточно полно. Это обусловлено во многом отсутствием механизма мотивации предприятий, организаций и отдельных граждан к созданию, освоению и использованию новых прогрессивных технологий; слабостью технологической базы ОПД (отсутствием высококачественных материалов, оборудования, оснастки, инструментов, измерительных средств, технических средств автоматизации); недостатками системы инвестирования технологических проектов; неразвитостью инфраструктуры, обеспечивающих заинтересованное взаимодействие научных, проектных, производственных, социальных, государственных и коммерческих структур в создании и реализации новых прогрессивных технологий.

Попытки выйти из этого тупика до настоящего времени производились бессистемно и непоследовательно. Стремление же максимально ограничить государственное регулирование процессов технологического развития в период перехода к рыночной экономике привело к еще большему углублению экономического и социального кризиса в стране.

Вышеизложенное вынуждает научные коллективы, отдельных ученых технологов и специалистов-практиков России приступить к изучению и анализу сложившегося в стране положения, поиску новых подходов к уменьшению технологического отставания России. Одним из таких возможных подходов является разработка и реализация Проекта программы работ по технологическому и духовному развитию России, опирающихся на систему рационально построенной научно-технологической, социальной, правовой и экономической политик.

Такой проект должен был бы явиться принципиальной основой системных работ по технологическому развитию страны. Он должен был бы определить сущность, цели, задачи, принципы и механизмы технологического развития, явиться исходной базой разработки и обеспечения функционирования системы такого развития $[27,28]$. Достаточно очевидно, что нельзя ожидать успеха технологического развития экономики России без создания его прочной концептуальной базы. Очевидно, такая база должна совершенствоваться по мере накопления и обобщения теоретических знаний и практического опыта в этой области $[18,19,36,37,38]$.

Современный научный и практический потенциал в области технологического развития различных видов ОПД, как в нашей стране, так и за рубежом позволяет сформулировать и обосновать ряд принципиальных положений Проекта технологического развития экономики России.

Проект программы технологического развития экономики России должен содержать основные положения и предложения, способные вывести страну из технологического кризиса, и, главное, обеспечить ее ускоренное эффективное развитие на базе активного создания и широкого использования прогрессивных технологий для системного решения проблем обеспечения эффективности народного хозяйства. Для реализации этих предложений предлагается разработать Программу технологического развития России.

Проект программы технологического развития предполагает активное участие государственных и негосударственных структур в разработке и реализации решений по важнейшим, кардинальным вопросам технологического развития.

Существующая Концепция и принятая Стратегия научно-технологического развития должны составить основу Программы технологического развития России на базе прогрессивных технологий, содержащей в первую очередь работы по определению принципов и созданию механизмов разработки и реализации различных 
отраслевых, региональных и других программ технологического развития, определению важнейших приоритетных направлений технологического развития.

Программа предполагает изменения в сфере собственности, разгосударствление собственности на многие технологии; создание наряду с различными формами государственной собственности, широкого класса частных и коллективных собственников, владеющих технологиями.

В Программе технологического развития России учитывается возможность использования отдельных элементов многочисленных разработок и программ, уже реализуемых на практике, но с учетом их трансформации к требованиям технологического развития страны.

Основной целью создания, внедрения и функционирования Системы технологического развития экономики России является обеспечение наиболее эффективного технологического развития ОПД во всей стране. Эта система охватывает все виды ОПД всех регионов, отраслей (подотраслей), предприятий, организаций и отдельных рабочих мест.

Системный подход $\mathrm{K}$ технологическому развитию экономики России обеспечивает выполнение работ по технологическому развитию ОПД как комплекса взаимосвязанных элементов на основе единой методологии, единой технологической политики и предусматривает ориентацию элементов системы на достижение основных целей системы.

Система технологического развития экономики России предусматривает организацию и выполнение работ по технологическому развитию ОПД на общероссийском, региональном, отраслевом (подотраслевом) уровнях, уровне предприятия, организации, отдельных рабочих мест.

Главными целями технологического развития экономики России являются повышение эффективности всех видов общественно полезной деятельности, рост производительности труда, сбережение ресурсов, повышение качества продукции, улучшение организации и условий труда, обеспечение благоприятных условий для повышения уровня жизни человека, сохранения и восстановления природы.

Основными задачами технологического развития экономики России предлагается считать $[2,21,22]$ сохранение, развитие и эффективное использование технологического потенциала России, отраслей народного хозяйства, регионов, предприятий, организаций и отдельных граждан; насыщение народного хозяйства прогрессивными технологиями для удовлетворения потребности в высокоэффективном выполнении ОПД; организацию и совершенствование технологической подготовки всех видов ОПД; создание, освоение и широкое использование прогрессивных технологий ОПд; организацию и совершенствование технологического образования и обучения; обеспечение технологической готовности к эффективному выполнению всех видов ОПд; обеспечение технологической дисциплины ОПД; тиражирование прогрессивных технологий ОПД и создание новых рабочих мест.

Построение и функционирование системы технологического развития экономики России должно базироваться на научных принципах построения систем, закономерностях технологического развития ОПД, научных знаниях, которые приводят к расширению, углублению и переосмысливанию ранее применявшихся понятий, подходов, методов и средств технологического развития ОПД.

Системный подход к решению проблем технологического развития России обеспечивает всесторонний охват технологическим развитием всех видов ОПД, всех смежных отраслей, предприятий, организаций и регионов России; создание устойчивого и саморазвивающегося механизма эффективного технологического развития ОПД.

Технологическое развитие экономики России должно опираться на всю совокупность научных знаний и их трансформацию в прогрессивные технологии и технологические решения ОПД [45]. Научные исследования и разработки должны больше ориентироваться на технологическое их приложение. В основе прогрессивных технологий и технологического развития должны быть новейшие достижения науки. Научные основы технологического развития экономики России должны обеспечить научную подготовку и реализацию технологического развития ОПД, высокий научный уровень и эффективность работ по технологическому развитию ОПД в России.

Научные основы технологического развития экономики России должны содержать: понятийный аппарат, необходимый для обеспечения общего, одинакового (по крайней мере для 
специалистов) понимания и освоения знаний о технологическом развитии ОПД; систему научных знаний о технологиях и технологическом развитии ОПД, в том числе, знаний о закономерностях технологического развития ОПД; фундаментальные методологические основы технологического развития ОПД; опытно-экспериментальную базу научных исследований и разработок проблем технологического развития ОПД.

Необходимым условием ТР экономики является совершенствование технологического образования и обучения персонала организаций.

Система технологического образования и обучения должна обеспечить подготовку высококвалифицированных специалистов по технолого-строению и использованию технологий в различных отраслях народного хозяйства и видах ОПД; своевременную технологическую подготовку и переподготовку кадров к выполнению ОПД; технологическое образование и обучение по перспективным направлениям развития ОПД; определение, формирование и приобретение базовых и специальных технологических знаний различных видов ОПД; технологическое просвещение и повышение технологической культуры населения; контроль технологических знаний и проверку качества выполнения обучаемыми различных контрольных заданий и видов ОПД; соответствие содержания технологического обучения и образования характеру и содержанию будущей ОПД обучаемых; сокращение сроков обучения и освоения новых технологий; обучение базовым и рабочим технологиям; ускорение освоения работниками новых технологических методов и средств различных видов ОПД; ускорение адаптации работников к конкретной ситуации и новым направлениям ОПД.

Технологи должны быть готовы к выполнению своих функций по определению наиболее целесообразных в техническом, социальном и экономическом отношениях характера и последовательности выполнения технологических процессов ОПД; по установлению методов осуществления этих процессов; по выбору необходимого оборудования, приспособлений, инструмента; по проектированию размещения оборудования и других средств технологического оснащения ОПД; по компоновке рабочих мест, цехов, подразделений; по технологическому нормированию ОПД; по обучению, освоению и использованию технологий.
Элементы технологического обучения должны представлять собой обучающие модули, каждый из которых с течением времени может совершенствоваться, изменяться или заменяться, что должно обеспечить технологическому обучению необходимый динамизм и возможность совершенствования в соответствии с изменяющимися условиями и требованиями ОПД.

Системы технологического обучения должны включать обучающие средства, контролирующие и тестирующие средства, базы данных и базы технологических знаний ОПД, средства управления технологическим обучением.

Необходимым условием технологического развития ОПД является соблюдение технологической дисциплины. Оно является обязательным для всех участников ОПД. Ответственность за состояние и нарушение технологической дисциплины должна возлагаться на исполнителей ОПД и их руководителей. Особо важную роль обеспечение технологической дисциплины приобретает в таких важных и потенциально опасных областях как, например, атомная энергетика, химическая промышленность, транспорт, добывающие и топливные области промышленности, строительство, здравоохранение и других [3].

Важным этапом является создание и реализация механизмов технологического развития экономики России. Под механизмами технологического развития понимается система методов и средств, норм, правил, предназначенная для воздействия на технологическое развитие с целью приведения его в требуемое состояние и для обеспечения его наибольшей эффективности. Данные механизмы должны обеспечивать поддержание технологического развития по заданному закону (правилу) или в установленных пределах значений некоторых регулируемых величин, характеризующих технологическое развитие, приложением управляющих воздействий к регулирующему органу объекта регулирования; благоприятные условия для эффективного решения проблем технологического развития; благоприятные последствия технологического развития; устойчивость технологического развития; рациональное использование интеллектуальных, материальных, информационных, финансовых и других ресурсов для технологического развития ОПД.

Основными механизмами технологического развития России являются социальные, пра- 
вовые, экономические, информационные и организационные механизмы. Все механизмы технологического развития должны быть согласованы между собой. Механизмы технологического развития ОПД в России должны являться единым, взаимосвязанным и скоординированным комплексом социальных, правовых, экономических, информационных, организационных и других средств и методов, которые бы обеспечивали эффективное технологическое развитие ОПД.

Механизмы технологического развития ОПД могут быть общероссийские (базовые), и механизмы, учитывающие особенности отраслей, регионов, предприятий и организаций России. Концептуальные положения о каждом из указанных видов общероссийских (базовых) механизмов технологического развития ОПД рассматриваются в следующих подразделах. Разработку механизмов технологического развития предлагается обеспечить при реализации Программы технологического развития экономики России.

Важнейшее место должно принадлежать социальным механизмам технологического развития.

Социальные цели технологического развития ОПД в России являются для него определяющими. Все их технологические достижения и нововведения могут оказаться бессмысленными, а то и вредными. Игнорирование социальной стороны технологического развития ОПД может оборачиваться не только серьезными экономическими, экологическими, но и политическими издержками. Социальные механизмы должны включать совокупность форм, методов, средств, норм и правил социального обеспечения и регулирования технологического развития ОПД в России и обеспечивать выполнение таких функций, как систематический учет, анализ, оценка, прогнозирование и планирование социальных воздействий на технологическое развитие ОПд и его последствия, а также их ресурсное, правовое, экономическое, информационное и организационное обеспечение.

Далее нам хотелось бы рассмотреть некоторые проблемы, характеризующие роль и место технологий в развитии экономики и обуславливающие научно - технологический прогресс.

Важную роль в процессах построения технологичной экономики России при институциональном направлении ее развития играет межотраслевое сотрудничество основанное на превалировании в менталитете производителя понимания значимости так называемого «технологического детерминизма» процесса воспроизводства.

Институциональная экономика занимается вопросами изучения механизма индивидуального выбора экономических агентов, способов, при помощи которых можно было бы применить разнообразные наборы институциональных ограничений. Традиции и нормы используются в качестве инструментов для побуждения экономических субъектов действовать согласно определенным правилам поведения в обществе.

Специалисты выделяют как отдельные направления развития институциональной экономики традиционный институционализм и современную институциональную экономику.

В последнем направлении выделяют неоинституционализм и новую институциональную экономику [43].

Традиционный институционализм образовался в конце XIX столетия. Его представители (Т. Веблен, Дж. Коммонс и др.) подчеркивают в своих исследованиях важность института для экономики, пытаются понять роль и эволюцию институтов. Именно представители этого направления ввели в экономику понятие «институт», утверждая, что на поведение человека существенно влияют такие институциональные образования, как государство, профсоюзы, корпорации, закон, институт семьи, этика.

С 70 годов XX века в развитии институциональной экономики появляется новое направление - неоинституционализм. Его представители (Р. Коуз, ДЖ. Стиглиц, Р. Познер) считают, что социальные институты имеют значение и поддаются анализу при помощи стандартных инструментов экономической теории. Они предполагают, что рынок действует в условиях совершенной конкуренции, отклонение от которой означает «провал рынка». В свою очередь, новая институциональная экономика занимается вопросами изучения различных структур управления государством, составляющими элементами которых являются организации (то есть институты), контрактная и хозяйственная система, институциональная структура общества. Толкование самого термина «институт» представителями этого направления было несколько расширено. Д. Норт выделяет в нем формальные и неформальные правила поведения, 
которые определяют взаимоотношения экономических агентов, также организаций. Кроме того, считается, что существуют институты механизмов принуждения, которые обеспечивают соблюдения правил (полиция, суды).

В зависимости от характера определения институциональных норм могут происходить разнокачественные изменения в экономической системе.

Технологический детерминизм представляет из себя теоретико-методологическую установку в философских и социологических концепциях и исследованиях на сведение понимания общественного развития к прогрессу техники, определяющим образом воздействующему на бытие, мышление и язык своих носителей. Сам термин возник в 20-х годах XX века в связи с бурными успехами в развитии науки и техники, нарастающей эффективностью их массового применения в развитии производства. Представители технологического детерминизма считают, что основной детерминантной социально-экономических и иных изменений в обществе являются более или менее крупные сдвиги в технике и технологической системе производства. Понятие «технология» означает в данном контексте соответствующие представления о мире, руководящие нашим восприятием всего существующего.

Взаимообусловленность признаков определенного направления предполагает экономическую целесообразность взаимосвязи «технологического детерминизма» и правила взаимовыгодности межотраслевых отношений. Под взаимовыгодностью межотраслевых отношений подразумевается возможность обеспечения экономических условий сотрудничества, определяемых, как минимум, возможностью воспроизводства ресурсов у каждого из производителей, участвующих в процессе воспроизводства в границах «народнохозяйственного пространства» и, как максимум, равновыгодностъю использования ресурсов у каждого из производителей этого пространства.

В условиях конкуренции эмпирический характер межотраслевых отношений в процессе воспроизводства определяет вторичность в менталитете производителя процесса обращения по отношению к процессу производства продукции. Трансформация в его менталитете оценки значимости межотраслевого сотрудничества происходит по мере повышения науч- но-технического уровня экономики еще при неоклассическом направлении. И выражается в столкновении, с одной стороны, понимания производителем приоритетности «технологического детерминизма» процесса воспроизводства, с другой - желания максимизировать эффект от производства своей продукции в отношениях с партнерами по процессу воспроизводства. Чем больше в менталитете производителя первое преобладает над вторым, тем лучше условия для приоритетности межотраслевого сотрудничества в процессе воспроизводства и тем большую значимость в развитии экономики приобретают принципы институционального направления.

Другой вывод, который можно сделать на основе предшествующего: чем лучше производитель понимает необходимость межотраслевого сотрудничества, тем меньше у него стремления к сохранению «коммерческой тайны», тем быстрее идет процесс выравнивания нормы прибыли, тем выше значимость научно-технического прогресса для развития экономики как экономики «народнохозяйственного пространства». В связи с этим, стремление к сохранению «тайны» собственного процесса воспроизводства как экономической категории, возникающей вследствие эмпирики межотраслевого сотрудничества производителей при неоклассическом направлении развития, может быть вызвано стремлением к сохранению тайны технологического процесса производства («технологической тайны») и стремлением к сохранению «тайны эффективности» (эффективности производства и сбыта продукта производства - производителем, или эффективности приобретения и эксплуатации средства производства - потребителем. Именно второе - стремление к сохранению «тайны эффективности» и является, сутью «коммерческой тайны» при межотраслевых «межфирменных» отношениях производителей.

Неоклассическое направление в условиях приоритетности конкуренции позволяет наиболее полно «проявиться» стремлению к сохранению как «коммерческой», так и «технологической тайны». Проявлению стремления к сохранению «технологической тайны» способствует отсутствие при внутриотраслевой конкуренции, как и при внутриотраслевых отношениях производителей вообще, «технологического детерминизма», свойственного межотраслевым отношениям производителей в процессе воспроизводства. 
Отсутствие «технологического детерминизма» процесса воспроизводства при внутриотраслевой конкуренции может объяснить и стремление производителей к «коммерческой тайне»: при внутриотраслевых отношениях производителей критерием являйся максимум времени сохранения этой тайны (одно из возможных проявлений критерия максимизации эффекта при монополизме производителя), что, понятно, не способствует развитию экономики страны, если ее воспринимать, как «народнохозяйственное пространство». Отсюда при приоритетности внутриотраслевой конкуренции органично «вплетение» в общую парадигму неоклассического направления проявление вторичности «технологического детерминизма» межотраслевого сотрудничества, что, как можно судить по опыту России, не способствует развитию технологически сложных производств.

Отсутствие «технологического детерминизма» при внутриотраслевых отношениях производителей (он отрицается единством процесса производства) приводит к тому, что возможности межотраслевых отношений при неоклассическом направлении проявляются post factum по отношению к процессу производства и сбыта отдельного продукта. «Технологический детерминизм» межотраслевого сотрудничества в процессе воспроизводства при данном направлении развития экономики «пробивает» себе путь через приоритетность «конкуренции технологий» при производстве аналогичных продуктов в процессе производства. Причем следует учесть, что приоритетность «конкуренции технологий» возрастает по мере роста монополизма. Преодоление противоречия, образуемого, с одной стороны, приоритетностью внутриотраслевой «конкуренции технологий» и отсутствием «технологического детерминизма» межотраслевых отношений, а с другой, по мере повышения научно-технического уровня экономики, необходимой приоритетностью межотраслевого сотрудничества в процессе воспроизводства, определяет сущность противоречия при переходе от неоклассического направления к институциональному направлению развития экономики.

Преодоление этого противоречия реально видится в создании механизма межотраслевых отношений производителей, создании тех «правил игры», которые препятствовали бы поведению кого- либо из производителей в границах «народнохозяйственного пространства» как монополиста. Надо учесть, что стремление к монополизму, при отсутствии каких-либо ограничений, связанных с необходимой приоритетностью межотраслевого сотрудничества, при саморегуляции экономики, как механизме, определяющем максимизирующее поведение производителя, теоретически не имеет никаких сдерживающих факторов: практически сдерживающим фактором выступает государство при проведении антимонопольной политики. Но это не фактор, вытекающий из процесса воспроизводства.

Именно поэтому «технологический детерминизм» межотраслевого сотрудничества в рамках неоклассического направления воспринимается производителем как вторичный по отношению к критериям развития отдельного производства. Опыт России показал, что это понимание места «технологического детерминизма» приводит к конкуренции уже между монополистами-производителями определенных видов продукции, т.е. к конкуренция «сильных» отраслей, когда контрагенты обвиняют друг друга в «неэффективном выполнении обязанностей». Следует подчеркнуть, что «разрешение» этих споров свидетельствует лишь о единовременной ликвидации противоречий. Однако ликвидация «причины» противоречий между монополистами невозможна при критериях сложившегося в настоящее время направления развития российской экономики.

Государство далеко не всегда может ликвидировать эти противоречия в рамках «законодательной инициативы», т.к. противоречия возникают не в рамках отношений «государство-производитель», а в рамках отношений «производитель-потребитель». То есть не при отношениях между государством и производителями, где государство, обычно, может использовать юридический аппарат принуждения. А при межотраслевых отношениях производителей в процессе воспроизводства. А эти отношения в рамках государственного законодательства, если и можно ликвидировать, то только при директивном руководстве экономикой, когда в рамках государственного ведения находятся все межотраслевые отношения между производителями в процессе воспроизводства.

Отличие рыночных отношений производителей от директивности управления состоит в том, что государство - при возможном введении «количественных ограничений» на макроуровне, 
не может законодательно регулировать деятельность микроуровня, т.е. отношения производителей в процессе воспроизводства. А потому рыночными могут быть признаны отношения производителей, если они являются свободными от государственного влияния даже в одной области - области межотраслевых отношений.

При понимании производителем приоритетности «технологического детерминизма» межотраслевого сотрудничества в процессе воспроизводства, максимизация эффекта, тем более в рамках единовременных мероприятий, практически невозможна, т.к. противоречит сущности межотраслевого сотрудничества. Дело том, что максимизация эффекта производителя реально, если возможна, то лишь при нулевом эффекте у потребителя продукции. Подобный принцип для потребителя неприемлем из-за невозможности в этом случае обеспечить расширенное воспроизводство ресурсов. Межотраслевое сотрудничество, если исходить из необходимости его долгосрочного функционирования в границах «народнохозяйственного пространства», не может быть основано на стремлении производителя к аккумуляции ресурсов, а должно быть построено на возможности обеспечения беспрепятственного их перелива в процессе воспроизводства.

Поэтому критерии развития экономики при приоритетности межотраслевого сотрудничества должны быть принципиально иные, препятствующие проявлению «силы» и «слабости» какой-либо отрасли или производства. При этой приоритетности не может быть ни «сильных», ни «слабых» отраслей или производств в границах «народнохозяйственного пространства»: все отрасли и производства одинаково нужны для процесса воспроизводства, если речь идет о целях и задачах народнохозяйственной деятельности. Институциональное направление, если его рассматривать в отношении российской экономики, таким образом, будет априори предполагать определенные связи производителей, обусловленные приоритетностью «технологического детерминизма» процесса воспроизводства. А потому будет направлено не на разрушение экономики, а на создание условий ее непрерывного функционирования: за счет сбалансированности условий межотраслевого сотрудничества производителей в границах «народнохозяйственного пространства» России.

Мы уже отмечали, что в настоящее время основным фактором определения конкурентоспособности российской продукции, как при производстве продукции внутри страны, так и внешнеторговых отношениях, служат мировые цены. Экономика России в настоящее время учитывает уровень мировых цен в качестве основного ориентира при ценообразовании и определении эффективности производимой продукции, зачастую даже не участвуя в международном разделении труда. Однако, в рамках директивного управления экономикой существовали несколько иные методы учета мирового уровня производимой продукции. В частности, вся новая научно-техническая продукция оценивалась: по уровню «А» - выше мирового уровня научно-технических достижений, по уровню «С»- соответствующая мировому уровню, по уровню «Н» - ниже мирового уровня. Продукция ниже мирового уровня практически не поощрялась к производству, а потому мировой уровень был критерием возможности внедрения в производство.

Подобное распределение по уровням качества производимой продукции, во многом, носило формальный характер, т. к. соответствие или не соответствие мировому уровню производимой продукции не отражалось на возможности воспроизводства ресурсов производителем этой продукции: ведь распределение ресурсов было централизованным. Оно позволяло российскому производителю не расплачиваться за несоответствие мировому уровню ликвидацией своего производства, а соответственно, ростом безработицы в стране и снижением материального уровня жизни трудящихся. В «столкновении» материальных интересов отдельных «сильных» производителей и «социальных» интересов жизнедеятельности населения директивность управления целиком защищала интересы последних: у первых не было возможности проявления, ни «силы», ни «интересов».

На настоящем этапе развития российской экономики одним из фактических следствий включения российской экономики в международное разделение труда является, пока что, лишь зависимость производства и экспорта российских ресурсов от уровня Мировых цен. Но при выработке экономической стратегии развития экономики России нельзя забывать, что международное разделение труда должно служить развитию экономики страны, а не наоборот, развитие экономики страны - международ- 
ному разделению труда.

Международное разделение труда будет целесообразно для России, если положительно отражается на ее потенциале, приносит пользу с точки зрения задач развития экономики как экономики «народнохозяйственного пространства», а не с точки зрения отдельных отраслей или производств. Ведь цели развития «экономики отдельных отраслей», как установлено, отнюдь не тождественны цепям развития экономики «народнохозяйственного пространства». Развитие экономики при ориентации на мировые цены, а соответственно и на потребности мирового рынка, неэффективно, если его оценивать с точки зрения целей развитая «народнохозяйственного пространства» России. С другой стороны, при ориентации на развитие «экономики отдельных отраслей» окажутся неэффективными цели развития российской экономики как экономики «народнохозяйственного пространства».

Отрицательные последствия ориентации на цели «экономики отдельных отраслей» для развитая российской экономики заключаются в двух аспектах.

1. В качестве конкурентных отраслей на первый план выходят производства, определяемые лишь «рентой первого рода», но не факторами, предполагающими приоритетность развития экономики за счет научно-технического прогресса. Иными словами речь идет о выигрыше от участия во внешнеторговой деятельности производств, имеющих лучшие природные факторы, т.е. факторы развития экономики, не зависящие от научно-технического уровня производства и от деятельности людей.

2. Подобное участие не возможно расценивать как выигрыш для экономики страны, если стратегическое развитие России оценивать с точки зрения повышения научно-технологического потенциала «народнохозяйственного пространства». Научно-технический прогресс, с точки зрения фактора времени, можно определить как «бесконечность», в то время как природные факторы, как и выигрыш от их использования, конечны и, во многом, невосполнимы. Превалирование экономической политики, опирающейся на выигрыш от использования только лучших природных факторов, в конечном итоге оборачивается стратегическим проигрышем страны. Тем более, если речь идет о такой стране, как Россия, восполнявшей издавна существенные государственные расходы, во многом, за счет сырьевых отраслей. Но если ранее, при директивности управления экономикой подобное формирование доходов, в силу централизованного распределения ресурсов, не было заметно для населения страны (централизованное распределение нивелировало проявление «силы» и «слабости» отраслей), то в настоящее время, при их аккумуляции в рамках только «сильных» сырьевых отраслей, это стало заметно для большинства жителей России.

Таким образом, перед руководством страны все яснее проявляется проблема необходимой переориентации деятельности сырьевых отраслей: с отраслей и производств, аккумулирующих доходы страны, на отрасли и производства, функционирующие в общехозяйственных процессах как субъекты «народнохозяйственного пространства» России. Институциональное направление развития российской экономики должно воплотить в жизнь новое содержание и принципы деятельности этих производителей, исходящие из приоритетности оценки эффективности отдельного производителя, в основном, как субъекта «народнохозяйственного пространства».

В этой связи единое «народнохозяйственное пространство» при директивности управления экономикой обеспечивалось принятием решений о межотраслевых связях производителей на государственном (народнохозяйственном) уровне. Теперь этого уровня руководства и этих принципов руководства межотраслевыми связями нет.

Следует подчеркнуть, что определение «народное хозяйство» при рыночных условиях хозяйствования отличается от определения аналогичной категории в условиях директивности управления экономикой. Й. Шумпетер включал в качестве основных признаков в «народное хозяйство» при рыночных условиях частную собственность, разделение труда и свободную конкуренцию [46].

Первые два принципа - частная собственность и разделение труда, не вызывают возражений. Сложность с третьим. На первый взгляд, он является необходимой принадлежностью первых двух. При частной собственности иного разделения труда, кроме как устанавливаемого при свободной конкуренции, как кажется, представить невозможно.

Однако, следует обратить внимание на то, что 
процесс воспроизводства может осуществляться при превалировании различных факторов. Если исходить из превалирования разделения труда, как исходного процесса при обеспечении приоритетности потребления продукции, то конкуренция производителей не может быть первичной по отношению к процессу эксплуатации продукта как ресурса, тем более, что приоритетность процесса обращения, как и процесса эксплуатации в процессе воспроизводства предполагает воспроизводство, выходящее за рамки процесса производства (сбыта) продукции.

Разделение труда - процесс конечный, заканчивающийся «налаживанием» межотраслевых связей производителей, необходимых для процесса воспроизводства. Он заканчивается постольку, поскольку заканчивается процесс конкуренции производителей за «место» в технологической цепочке, определенной процессом воспроизводства продукции. Таким образом, производитель не может все время конкурировать в процессе производства, но должен все время участвовать в межотраслевом сотрудничестве в процессе воспроизводства - такова азбука процесса воспроизводства.

А поэтому эмпирика межотраслевых отношений в процессе воспроизводства - явление временное, т.к. по мере повышения научнотехнического уровня экономики «технологический детерминизм» процесса воспроизводства все более и более обуславливает необходимость устойчивости и долгосрочности межотраслевого сотрудничества. Правда, эта эмпирика, в рамках критериев роста экономики промышленноразвитых стран, при «межфирменных» отношениях преодолена быть не может. Но по мере развития экономики, повышения ее научнотехнического уровня, предприятия все более и более будут стремиться к превращению экстернальных трудностей в интернальные, т.е., проще, к объединению, ограничиваемому принципами «убывающей доходности управления». Однако, только в российской экономике в условиях рынка появляется возможность превращения «экономики отдельных отраслей» в экономику «народнохозяйственного пространства», т.е. при определенных условиях, преодоление «убывающей доходности управления».

Если процесс создания устойчивых и приоритетных межотраслевых связей затягивается, то, как видно из опыта России, Происходит зачастую необратимое превращение диверсифици- рованной экономики в «экономику отдельных отраслей». Итак, при устойчивых межотраслевых отношениях производителей конкуренция - явление второстепенное, т.к. речь идет о необходимой Приоритетности межотраслевого разделения труда, необходимой для процесса воспроизводства. Приоритетность конкуренции кончится там и тогда, где и когда эмпирически возникающие в процессе воспроизводства определенных продуктов межотраслевые связи производителей выльются в устойчивую приоритетность задач развития экономики России как экономики «народнохозяйственного пространства».

Поэтому, понимая некоторую противоречивость утверждения Й. Шумпетера, по ряду положений он был прав. В частности, основной особенностью категории «народного хозяйства» («народнохозяйственного пространства») является стремление к состоянию равновесия - «никогда не достигающемуся, но всегда «желаемому». Это состояние, по Й. Шумпетеру, «меняется потому, что меняются показатели» («Мы понимаем отдельные процессы в народном хозяйстве как частные проявления тенденций к какому-то состоянию равновесия, но не всегда одному и тому же: положение идеального, всегда «желаемого» (подсознательно, разумеется) состояния народнохозяйственного равновесия меняется, потому что меняются показатели») [46].

Из этого следует, что равновесное (сбалансированное) состояние экономики в условиях «свободного» рынка, в условиях постоянного, не обусловленного никакими «правилами игры» изменения показателей, возможно лишь эмпирически и лишь как функция механизма межотраслевых отношений производителей. «Не достигаемым» состояние равновесия будет до тех пор, пока в отношениях производителей будет превалировать эмпиризм, конкуренция и «коммерческая тайна».

Ликвидация этих явлений в экономике, переход к межотраслевым отношениям, основанным на правилах поведения производителей, определяемых приоритетностью межотраслевого сотрудничества в границах «народнохозяйственного пространства» и «прозрачностью информации», позволит обеспечить сбалансированность экономики как наилучшее состояние ее функционирования. Это состояние может быть достигнуто при критериях институционального направления развития. «Прави- 
ла игры», как правила поведения производителей в процессе воспроизводства, оставляют «на совести» самих производителей-партнеров установление конкретных «количественных параметров» межотраслевого сотрудничества, и поэтому достижение равновесного состояния экономики как априорного ее «количественного состояния» невозможно.

С другой стороны, вызывает сомнение идея Й. Шумпетера по рассмотрению сбалансированности экономики как основы функционирования производителя в процессе межотраслевого сотрудничества в границах «народнохозяйственного пространства». Поведение производителей в условиях, когда некоторые из процессов «выходит за переделы обычных рамок, меняют привычный ход и не могут быть поняты с точки зрения «кругооборота» [46], может быть непредсказуемо только в том случае, если речь идет об эмпирике отношений производителей, при отсутствии каких-либо априорных ограничений в поведении каждого из них. В сущности, именно эти отношения производителей и имел в виду Й. Шумпетер.

Но если речь идет об ограничениях, определяемых «правилами игры», одним из основных при которых является достижения взаимовыгодных отношений производителей в границах «народнохозяйственного пространства», то эти ограничения «автоматически» ставят производителей в условия, при которых легко достичь понимания между ними при осуществлении, пользуясь терминологией Й. Шумпетера, «кругооборота», или, иными словами, при осуществлении непрерывного процесса воспроизводства. Эти «правила», при приоритетности межотраслевого сотрудничества, основанного на взаимовыгодности отношений, не позволят «монополисту в производстве» выступать «монополистом в поведении» по отношению к партнерам по процессу воспроизводства. И поэтому поведение производителя, вне зависимости от места его продукции на рынке, всегда будет определяться критериями, которые обеспечат сбалансированность экономики в целом.

Итак, состояние сбалансированности является прерогативой экономики, построенной на приоритетности межотраслевых отношений. Приоритетность внутриотраслевых отношений (внутриотраслевой конкуренции) из-за отсутствия «технологического детерминизма» отношений производителей, не может породить равновесной ситуации и равновесной экономики. Это утверждение подтверждает положение о том, что основой создания единого «народнохозяйственного пространства» России должна служить приоритетность межотраслевых, а не внутриотраслевых отношений производителей.

Важно, что развитие межотраслевых отношений в условиях рынка не может осуществляться на основе законодательных актов, в рамках отношений «государство-производитель». Единое «народнохозяйственное пространство» требует введение «правил игры», определяющихся «неформальными», выработанными самими производителями, ограничениями, действующими для всех производителей в границах этого «пространства». Укрепление демократии в развитии экономики при институциональном направлении будет состоять в вытеснении элементов отношений «государство-производитель» из сферы межотраслевых отношений производителей отношениями «производитель-потребитель».

Этатистские функции постепенно обретут свою сферу - сферу проведения мероприятий, связанных с функциями обеспечения жизнедеятельности населения и национальной безопасности государства. Влияние государства на производителя за счет разного рода льгот и трансфертов, т е. в форме частичного централизованного распределения ресурсов, заменится контролем самих производителей над процессом воспроизводства ресурсов в границах «народнохозяйственного пространства». Контролем с помощью «правил игры» при соблюдении приоритетности «технологического детерминизма» процесса воспроизводства.

Таким образом, приоритетность отношений производителей, определяемая соблюдением ограничений в рамках отношений «государствопроизводитель», при институциональном направлении развития экономики заменится приоритетностью отношений, определяемых в процессе межотраслевого сотрудничества менталитетом производителей и неформальными ограничениями в рамках отношений «производитель-потребитель». Если следовать логике подхода, то высшей формой проявления демократии в экономической политике государства будет ситуация, при которой межотраслевые отношения производителей займут основное место в процессе воспроизводства, при жестко определенном «ареале» отношений «государство-производитель». 
Тезис о приоритетности межотраслевых отношений производителей в процессе воспроизводства, несомненно, вызовет возражение сторонников неоклассического направления развития производства. Возражения, среди прочего, могут сводиться к, казалось бы, неопровержимому доводу, когда речь идет о научнотехническом прогрессе. «Все предшествующее развитие доказало, что двигателем научнотехнического прогресса является конкуренция». Тем более, что ее влиянию посвящено так много работ: для примера можно сослаться на основополагающую работу Р. Форстера «Обновление производства: атакующие выигрывают» [44].

Ответ на эти возражения следующий: внутриотраслевая конкуренция является двигателем научно-технического прогресса постольку, поскольку в рамках воспроизводства, ограниченного процессом производства, научно-технический прогресс способствует монополизму производителя, внедряющего научно- техническое новшество. Но монопольное положение производителя, желающего как можно дольше сохранить «технологическую тайну», отражающуюся в возможности максимизации эффекта за счет этого новшества только у этого производителя, тормозит научно-технический прогресс, если последний рассматривать с точки зрения роста экономики «народнохозяйственного пространства».

Научно-технический прогресс при приоритетности внутриотраслевой конкуренции («внутриотраслевой» научно-технический прогресс) тормозит научно-технический прогресс при приоритетности межотраслевого сотрудничества («межотраслевой» научно-технический прогресс). Отсюда развитие экономики «народнохозяйственного пространства» России при первичности фактора научно-технического прогресса можно будет воспринимать как диалектическое «единство противоположностей», при котором, если речь идет о «народнохозяйственном пространстве», «межотраслевой» научно-технических прогресс должен постепенно вытеснять «внутриотраслевой».

В отличие от внутриотраслевых отношений, производители при межотраслевых отношениях не имеют «свободы сбыта» продукции, так как «технологический детерминизм» процесса воспроизводства предполагает предопределенность потребителя. В случае межотраслевых отношений можно говорить о влиянии потре- бителя на процесс производства, но при вторичности стоимостных категорий, определяемых возможностью максимизации эффекта от сбыта продукции производителем, и при первичности стремления к сбалансированности отношений производителя и потребителя, при первичности категорий, определяемых технологией производства, в частности, категорией «технологический детерминизм».

Однако следует учесть, что в реальной практической деятельности производителя влияние фактора «технологического детерминизма» трудно отделить от влияния критериев оценки деятельности отдельного производителя на основе стоимостных категорий. Каждая из категорий в процессе воспроизводства выступает как квазинеобходимая, а потому не может быть «абсолютной». Например, производитель, стремясь к максимизации эффекта, всегда понимает, что добиться этого критерия невозможно, если хочешь добиться беспрепятственного и долгосрочного процесса воспроизводства своей продукции.

С этой точки зрения здесь важен подчеркнутый еще Й. Шумпетером факт, определяющий развитие страны как народнохозяйственного комплекса: «Изменение одной цены в принципе влечет за собой изменение всех цен, пусть даже некоторые из них столь незначительны, что их практически не возможно обнаружить. И все эти изменения в свою очередь оказывают на них обратное влияние. В социальных науках всегда приходится иметь дело с таким клубком влияний взаимосвязей и взаимозависимостей,- в котором легко потерять нить, ведущую нас от причин к следствиям [46].

Это относится к технологической взаимосвязи производителей, точнее, «технологической составляющей» научно- технического прогресса, если этот прогресс рассматривать в границах «народнохозяйственного пространства». Научно-технический прогресс при межотраслевом сотрудничестве производителей на практике сложнее выявить и сложнее рассчитать, чем научно-технический прогресс при внутриотраслевой конкуренции, но он более плодотворен для развития экономики к народнохозяйственного пространства».

Таким образом, можно констатировать, с некоторой долей условности, два вида научнотехнического прогресса, каждый из которых связан со своим направлением развития эконо- 
мики, являясь результатом когерентности факторов в рамках каждого из этих направлений.

Резюмируя аспекты исследования, приведенные в настоящей работе, отметим следующее. При неоклассическом направлении научно-технический прогресс связан с внутриотраслевой конкуренцией, критериями и отношениями производителей, свойственными этому направлению, что можно считать менее плодотворным с точки зрения технологического развития экономики страны из-за того, что прогресс экономики в этом случае осуществляется не как прогресс «народнохозяйственного пространства», а как прогресс отдельных отраслей или производств при развитии экономики как «экономики отдельных отраслей». Другая трактовка научно-технического прогресса связана с повышением технологического уровня экономики и укреплением межотраслевого сотрудничества, приоритетность которого характерна для институционального направления развития. При этом направлении развития научно-технические новшества порождаются не необходимостью «выживания» производителя в конкурентной борьбе с производителями аналогичной продукции, а необходимостью укрепления межотраслевого сотрудничества с потребителями, внедряющими в свое производство новый продукт. Технические (технологические) параметры нового продукта в этом случае предполагают повышение технических (технологических) параметров продукта у потребителя нового продукта.

Поэтому акцент в расчетах эффективности продукта при институциональном направлении должен быть перенесен: с оценки эффективности его сбыта с точки зрения производителя продукта, на оценку эффективности его исполь- зования - с точки зрения потребителя ресурса. Эффективность продукта как продукта производства, рассчитываемая с точки зрения производителя - при неоклассическом направлении, должна уступить приоритетное место расчету эффективности использования этого продукта как средства производства или ресурса потребителя - при институциональном направлении развития экономики России.

Повышение технологического уровня экономики, вследствие приоритетности «технологического детерминизма» межотраслевого сотрудничества, проявится при институциональном направлении в повышении этого уровня по технологическим цепочкам в границах «народнохозяйственного пространства» России.

Реализация Программы технологического развития экономики России предусматривает рост ВВП в 2-3 раза, улучшение социального климата в России, сохранение и развитие технологического потенциала, предотвращение утечки умов, вывод России к 2025 году в число ведущих, технологически развитых стран мира, позволяющих всем гражданам «жить по человечески» (Путин В.В., см. Введение).

При подготовке отчёта были использованы, обобщены и систематизированы основные научные разработки и проектные материалы ведущих советских и российских, а также зарубежных учёных и специалистов в области инновационно-технологического развития производства конкурентоспособной продукции и управления этими процессами: Брюнина В.Н., Глисина Ф.Ф., Деминга Э., Дресвянникова В.А., Дрогобыцкого И.Н., Ивантера В.В., Комарова М.А., Максимцова М.М., Малышева В.Л., Малышева Н.И., Петракова Н.Я., Сэмуэльсона П., Хотулёва А.В., Янга С. и других авторов.

\section{Библиографический список}

1. Л. фон Берталанфи Общая теория систем - Критический обзор. Исследования по общей теории систем.М.: Прогресс, 1969.

2. Брюнин В.Н., Глисин Ф.Ф., Меньшиков С.М., Хотулев А.В. Концепция технологического развития России: (проект) - М.: АТН РФ, ИТЦ «ИНТЭКС» предприятия «Новинтех-ИНКОР» МЭСИ, МЦТСПО.-1992.

3. Винер Н. Кибернетика, или Управление и связь в животном и машине.- М.: Советское радио, 1958.

4. Винер Н. Нелинейные задачи в теории случайных процессов.-М.: ИЛ., 1961.

5. Винер Н. Кибернетика, или Управление и связь в животном и машине. 2-е изд.- М.: Советское радио, 1968.

6. Винер Н. Человек управляющий.- СПб.: Питер., 2001.

7. Глисин А.Ф. Некоторые особенности развития современной инновационной экономики // Сборник статей международной научно-практической конференции «Актуальные проблемы экономики». Часть 1. Ответственный редактор Сукиасян А.А., Издательство: Аэтерна, Уфа - 2015 - С. 92-98. 
8. Глисин Ф.Ф., Калюжный В.В. Оценка эффективности научной и инновационной деятельности в зарубежных странах и в России // Инновации. - 2015. - № 6. - С. 32-37.

9. Глисин Ф.Ф., Калюжный В.В. Прогнозирование показателей научной деятельности // Инновации. - 2014.№ 11(193). - С. 37-44.

10. Глумаков В.Н., Максимцов М.М., Малышев Н.И. Стратегический менеджмент: Практикум - М.: Вуз. учебник, 2006.

11. Деминг У. Эдвард Выход из кризиса: Новая парадигма управления людьми, системами и процессами. Пер. с англ.-М.: Альпина Бизнес Букс, 2007.

12. Деминг У. Эдвард Новая экономика (пер. с англ. Т. Гуреш).- М.: Эксмо, 2006.

13. Дресвянников, В.А. Управление деятельностью организации как комбинация управления процессом, знаниями и состояниями / В.А. Дресвянников // Менеджмент в России и за рубежом.-2016. - № 6.- С. 70-74.

14. Дресвянников, В.А. Интеллект и информация: назначение, содержание, работа: Монография. [Электронный ресурс] Издательство: Издательские решения. Litres.ru, 2016.

15. Дресвянников, В.А. Интеллектуальный менеджмент. Формирование информационного ментального пространства. Экономика и менеджмент инновационных технологий. 2015. № 2 [Электронный pecypc]. URL: http://ekonomika.snauka.ru/2015/02/7135

16. Дресвянников, В.А. Управление знаниями организации: Учебное пособие. М.: КНОРУС, 2016.

17. Дресвянников, В.А. Менеджмент организации: Учебное пособие / В.А. Дресвянников, А. Б. Зубков, О.Е. Чуфистов. [Электронный ресурс] Саратов: Вузовское образование, 2014. Режим доступа: http://www.iprbookshop. $\mathrm{ru} / 23580$. ЭБС «IPRbooks».

18. Дрогобыцкий И.Н. Системный анализ в экономике: Учебник - М.: ЮНИТИ-ДАНА, 2017.

19. Дрогобыцкий И.Н. Системные основы организационного менеджмента // Теория и практика институциональных преобразований в России, - 2012 - Выпуск 23 - С. 1-40.

20. Друкер Питер Ф. Задачи менеджмента в XXI веке.: Пер. с англ.: - М.: Издательский дом «Вильямс», 2004.

21. Ивантер В.В. Инновационно-технологическое развитие экономики России: проблемы, факторы, стратегия - М.: Макс-Пресс, 2005;

22. Ивантер В.В. Прогноз технологического развития экономики России с учетом новых мировых интеграционных процессов - М.: ИНП РАН, 2006;

23. Ивантер В.В. Прикладное прогнозирование национальной экономики. Учебное пособие.-М.: Экономисть, 2007;

24. Ивантер В.В. Перспективы развития экономики России на ближайшие 20 лет // Вестник РАН,-2008,- № 2 Том 78.

25. Ивантер В.В. У российской экономики есть потенциал роста // Вестник Финансового университета - 2015,№ $3-$ C. $18-25$.

26. Игнатьева А.В., Комаров М.А., Максимцов М.М. и др. Менеджмент: Учеб. для вузов / Под ред. проф. М.М. Максимцова, М.А. Комарова. - 2-е изд., перераб. и доп.- М.: «ЮНИТИ-ДАНА», 2014.

27. Клейнер Г.Б. Эволюция системы экономических институтов в России.- М.: ЦЭМИ РАН, 2003.

28. Клейнер Г.Б. Макаров В.Л. Микроэкономика знаний.- М.: Экономика,, 2007.

29. Клейнер Г.Б. Системная парадигма и системный менеджмент // Российский журнал менеджмента - 2008. № 3, Том 6,- С. 27-50.

30. Малышев В.Л. От экономики соперничества к экономике сотрудничества.- М.: Экономика, 2010.

31. Малышев В.Л. Государство и механизм.-М.: Экономика. 2012.

32. Малышев В.Л. От производителя к продукту.-М.: Экономика. 2013.

33. Малышев В.Л. О возможности институционального первенства России. - М.: Экономика. 2016.

34. Максимцов М.М., Малышев Н.И. Содержание и задачи производственного (операционного) менеджмента // Экономика и управление: проблемы, решения. - 2015. - № 9.- С. 75-80.

35. Малышев Н.И. Шевченко С.С. Системные закономерности и механизмы управления технологическим развитием производственных систем // Управленческие науки в современном мире.- 2016. - № 1. - С. 354357.

36. Меньшиков С.М., Цаголов Г. Бизнес-долголетие Новый тип российского миллионера - М.: ЭКСМО, 2007

37. Меньшиков С. М. Анатомия российского капитализма - М.: Международные отношения, 2008.

38. Петраков Н.Я. Кибернетические проблемы управления экономикой.- М.: Наука, 1974

39. Петраков Н.Я. Управление хозяйственными системами.-М.: Знание, 1975

40. Полтерович В.М. Экономическое равновесие и хозяйственный механизм. - М.: Наука, 1990

41. Полтерович В.М. Элементы теории реформ.-М.: Экономика, 2007 
42. Современный менеджмент: Учебник / Под ред. М.М. Максимцова, В.Я. Горфинкеля.- М.: Вузовский учебник: НИЦ ИНФРА-М, 2015.

43. Самуэльсон П., Нордхаус В. Экономика. - М.: «Вильямс», 2014.

44. Форстер P. Обновление производства: атакующие выигрывают.- М: Прогресс.- 1987 - С. 208.

45. Хотулёв А.В. Система технологического развития России, основные принципы ее построения // Перспективы развития единого научно-технологического и образовательного пространства Содружества Независимых Государств: материалы секционного заседания Международной конференции X Международного форума «Высокие технологии XXI века», 23 апреля 2009 г.: в 2 ч. / Рос. Фонд развития высоких технологий, Ассоциация техн. ун-тов, МГТУ им. Н.Э. Баумана. - 2009.- Ч. 1.- С. 139-143.

46. Шумпетер Й. Теория экономического развития. - М.: Прогресс. - 1982.- С. 75-86.

47. Янг С. Системное управление организацией. Пер. с англ. под ред. С.П. Никанорова, С.А. Батасова. - М.: «Советское радио».-1972.- С. 456.

48. Указ Президента РФ от 01.12.2016 N642 «О Стратегии научно-технологического развития Российской Федерации», / Консультант Плюс, 1992-2018 [Электронный ресурс].- Режим доступа: http:/www.consultant.ru/ law/hotdocs/48053.html 